From: Hayhoe, S. (2019). Cultural Heritage, Ageing, Disability \& Identity: Practice, and the Development of Inclusive Capital. Abbingdon, UK: Routledge.

\title{
Chapter 4: Inclusive Capital and Human Value
}

Word Count: 8,274 Words

Acknowledgement: This project has received funding from the European Union's Horizon 2020 research and innovation programme under grant agreement No 693229 - Appendix A.

\section{Introduction}

Building on my last two chapters, this chapter describes how we learn inclusive capital, and how inclusive capital forms our identities. This description of inclusive capital is formulated to develop an analysis of the cases in the following two sections of this book; this chapter was also developed to inform a project undertaken for the European Commission, evaluating cultural services for adults with disabilities.

My observation that we develop inclusive capital evolved out of a survey of previous philosophies of human value, the ideas they shared and their description of the value of capital. In common with these previous philosophies, I was interested in the way human value influenced identity and behavior, and its ways of thinking about motives and desires. Human value also seemed to be an effective way of understanding our personal knowledge, activity and skills, and how these elements shape our personality, memory and character traits.

For instance, in the study of education, knowledge of books and their contents can hold inclusive value; study skills we are taught in class, or that we learn through practicing 
these study skills can hold inclusive value; what we call the "good" or "bad" behavior and habits that we learn, which are thought to make us productive members of society, such as queuing and being polite can hold inclusive value; the way we learn to dress or the way we talk to others can hold inclusive value to us and those around us.

Moreover, the informal knowledge we learn outside formal classes also derives value for us as individuals. This value can be informal knowledge and skills we learn in the school yard, such as who is popular, or who should be avoided and why; what clothes we need to wear to make ourselves accepted by our peers. Alternatively, we can value when to use certain types of language, such as slang and swearing, and with whom this language is socially acceptable.

Our moral and immoral knowledge, such as the rules of bullying, and how to exclude others that don't fit our rules of social acceptability can also hold a more negative value; and hierarchies of power in the schoolroom or school yard, or the development of sexual and romantic relationships can be said to hold value, as they are valued.

What's more, even moral values we often don't align ourselves with can be said to hold value to those who hold those moral beliefs. For instance, a knowledge of how to steal, what is acceptable to steal, and who the most vulnerable members of society are can be said to have pernicious value.

In common with the topic of this book, knowledge of our interactions in museums and national parks can be valued and hold value. These values can be the measurement of our knowledge and our motivation for visiting museums and national parks that for us hold cultural value.

Value can also be said to be in the subconscious habits that dictate the way we learn to gain access to museums. Value is also in the understanding or lack of understanding of the importance of museums and national parks. The outcome of this knowledge and practice can 
also be a sense of inclusion and a feeling of well-being that visiting cultural institutions brings, as it makes us feel valued.

Consequently, and as I illustrated above, value does not have good or bad qualities, as morals themselves are valued according to our own, individual values.

In the previous two chapters, I talked about the creation of different institutions for people with disabilities, and the practical and the social worlds that people with disabilities live in. I also argued that the social world of disability is the most dangerous of these two worlds. I finished this argument by finding that disabled people's identities can be roughly categorized in three ways: people who have early disabilities, and whose peers are mostly disabled; people who acquire an impairment or difficulty in childhood, and so must go through the transition from mainstream institutions to institutions for people with disabilities; people who become disabled in later life, but who only know mainstream institutions as children.

In this chapter, I develop this idea by arguing that all three identities, as well as the practical skills needed for inclusion, are developed by different forms of values of noneconomic capital. What's more, I also argue that these disabled identities demand different forms of access strategies, from technical and educational access, to access based on spaces and places alone. This is what the widest used models of disability, such as those described as the medical and the social models of disability, have done little to emphasize in the past.

I start this discussion by outlining a survey of philosophy on human values that evolved into theories of non-economic capital, and by describing how the philosophical history of human capital as value evolved. 


\section{Adam Smith and Karl Marx on human labor and human value}

The observation that human skills and knowledge had value was first understood in the eighteenth century, and became a driving force of the Enlightenment and the British industrial revolution. Arguably, the first method of valuing knowledge and behavior was first discussed in 1776 by the Scottish philosopher and founder of Capitalism, Adam Smith, in the first edition of his book, The Wealth of Nations, as one of three classes of economic capital. ${ }^{\mathrm{i}}$

In The Wealth of Nations, Smith also suggested that capital should be measured through quantifiable human labors, such as how many of a certain product a human made. This distinction between human labors and the work people do, rather than the human body as capital, was an important distinction to make.

As Smith observed, before the industrial revolution human capital had mostly been thought of as a "thing," like gold, money, land or tools. These systems had mostly existed in slave-based or feudal societies, and Smith himself wrote in the last full century of legalized Western slavery.

Consequently, in Western societies, humans from "lower" social strata were merely valued as possessions or chattels, which could be bought, sold, owned, and treated as commodities. In the feudal and semi-feudal systems that still existed at the time of Smith, workers were also tithed to their land and homes, with little chance of social or cultural development.

During the industrial revolution, Smith felt, humans were valued as transferrable machines or tools, which could be used to make products for sale, or to make more tools or machinery. Consequently, money could be used to buy commodities like land, which could be worked by human labor for temporary wages, and supported mechanized tools to make further profits. For Smith, this cycle was virtuous and made the capitalist system a self- 
supporting and quantifiable cycle of capital value. Subsequently, the capital value humans possessed was,

the acquired and useful abilities of all the inhabitants or members of the society. The acquisition of such talents, by the maintenance of the acquirer during his education, study, or apprenticeship, always costs a real expense, which is a capital fixed and realized, as it were, in his person. Those talents, as they make a part of his fortune, so do they likewise of that of the society to which he belongs. The improved dexterity of a workman may be considered in the same light as a machine or instrument of trade which facilitates and abridges labor, and which, though it costs a certain expense, repays that expense with a profit. ${ }^{\text {ii }}$

Smith's belief that labor was a quantifiable valuable commodity later inspired the writing of the German philosopher and economist Karl Marx in his book, Das Kapital (Capital), first published in 1867. ${ }^{\text {ii }}$ Following the British and US abolition of legalized slavery in the nineteenth century, Marx observed the mistreatment of human labor and its value continued to be exploited by the capitalist system. This exploitation was the result of the misappropriation of the value of labor embedded in the commodity it reproduced, or as an abstract value of capital. Subsequently, writing from the standpoint of economic human labor, Marx felt that the industrial revolution in Britain \& Ireland in particular fundamentally changed the value of human labor as capital.

Prior to the industrial revolution, Marx wrote, human labor - which can be seen to akin to Smith's value of human labor - had a different social and psychological value to physical capital. This quality was due to the inter-generational loss of skills that serfs and peasants previously had as craftspeople, despite their oppression by their feudal landlords that is to say, these serfs and peasants had taught themselves values and passed on this value through learning and skills to their families. 
Marx argued that a consequence of the industrial revolution was that it changed the nature of human labor value psychologically. Subsequently, human labor value in the nineteenth century had subsequently been deprived of the relative freedom of thought that existed in the feudal economy through industrial and agricultural products.

Along with the useful qualities of ... products themselves, we put out of sight both the useful character of the various kinds of labor embodied in them, and the concrete forms of that labor; there is nothing left but what is common to them all; all are reduced to one and the same sort of labor, human labor in the abstract.

Let us now consider the residue of each of these products; it consists of the same unsubstantial reality in each, a mere congelation of homogeneous human labor, of labor power expended without regard to the mode of its expenditure. All that these things now tell us is, that human labor power has been expended in their production, that human labor is embodied in them. When looked at as crystals of this social substance, common to them all, they are - Values. ${ }^{\text {iv }}$

Importantly, Marx argued that by deskilling the industrial workforce the industrial revolution substantially decreased the generational value of individual human labor. This deskilling of the workforce, Marx continued, would lead to a more collective consciousness, and provoke a revolution that would change the nature of society's self-awareness and selfvaluation.

Although partly inspired by Smith's quantification of human behavior and thought, Capital represented a departure from Smith's ideas on the capital value of human labor. Importantly, although Smith referred to human labor as a valuable moral activity, he had not seen human behavior as exploitable, or thought of humans in terms of individual consciousness. Marx did. Arguably, Smith also didn't write about all labor as having equal 
value, or as the value of sentient beings in control of their minds, as to Smith labor was moral and not political. Contrariwise, Marx argued labor was highly political, and morals were not part of our motivation but used a tool of capitalist exploitation of value.

Marx's interpretation of capital was also importantly the first development of ideas on capital value through a social and economic endeavor, which affected the psychological value of a community. This was an important step because, although writers such as Samuel Howe whom I wrote about in the last chapter discussed community behaviors in this era, he believed that behavior was dependent on God-given morals. Marx was subsequently amongst the first philosophers to discuss human learning and behavior as having communitarian value without recourse to traditional moral judgements.

\section{Pierre Bourdieu on human capital as qualitative division}

For over a hundred years, Marx's theory that human labor had essential quantifiable and economic value was dominant in the writing of Western social and economic philosophy. However, in 1979 the French social philosopher Pierre Bourdieu published Distinction, which featured the results of a different type of survey of human capital value in 1960s

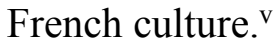

Instead of providing distinctive quantitative economic value between social classes, Bourdieu described two new forms of capital value: social capital, such as the value of knowledge and habits that affected people's employment status, where they lived, and what their title was; and cultural capital, which was the value of knowledge and habits that effected people's level of education, intellectual skills and aesthetic tastes.

Social and cultural capital values, Bourdieu felt, were acquired from birth through observational as well formal learning, and it was these values that provided social and cultural distinction. This meant that a person's immediate environment, formal education and 
workplace played as much of a role in developing value as they did in forming industrial skills through learning to labor.

Consequently, according to Bourdieu social class was not just restricted to accumulating material wealth, as Marx had argued. Instead, Bourdieu believed that behavior, religious and political beliefs, and other notional human characteristics, which simply exist as a state of mind, could quantify value as social status.

Importantly, Bourdieu believed it was the value of social and cultural capitals that also provided distinctions of knowledge and habits by societies as a whole. Subsequently, it was also the value of these social and cultural capitals that divided access to education, institutional memberships, and accepted accents and language.

What's more, Bourdieu argued this division of capital effected social and cultural standing, and created a valued identity that attempted to back-up what was felt to be a social and cultural superiority. Like Marx, Bourdieu also suggested that social and cultural capitals created complex and subtle differences in value between communities, which informed different ways of thinking.

However, despite their belief in communities with similar psychologies, there are significant differences between Marx and Bourdieu's understanding of capital value. Most particularly, Bourdieu felt that, given the correct notional capital values, having little money could raise social status rather than diminish it.

For example, Bourdieu wrote that people could have high social and cultural value but lack money if they were highly educated, led a Bohemian lifestyle or had avant-garde tastes in written or visual art. Furthermore, Bourdieu felt that if people were relatively poor but had a high level of education and "developed tastes," it improved their social and cultural value. In these circumstances, wealth was thought to be "showy" and "affected." 
There are criticisms of Bourdieu's descriptions of social and cultural capitals. For example, critics observed that Bourdieu's theory was full of generalizations about what was thought of as social status. ${ }^{\text {vi }}$ Others argued that Bourdieu's writing was culturally biased, and that his observations as to what constitutes a social and cultural capital was Franco-centric. ${ }^{\text {vii }}$

Likewise, some critics felt that Bourdieu's belief in a rigid social and cultural community that had no fluidity was naïve, and had little consideration of social evolution. ${ }^{\text {viii }}$ These critics also observed that social mobility blurred the lines as to what a working class or middle-class person was, and that Bourdieu overlooked the way working class behaviors had cache and value.

However, despite his critics Bourdieu's theory of capital value provided a framework that allowed for analysis of social exclusion as a form of distinction, and the hidden values of social exclusion within communities. Moreover, many academics felt Bourdieu's description of social and cultural capitals could be applied to loosely-defined categories of socially excluded people, such as disabled people. ${ }^{\text {ix }}$ This application allowed these categories of people to be imagined as a community that was bounded by a partial social exclusion.

More importantly, and as a professional educator, Bourdieu explained how the values of knowledge and habits that could lead to social and cultural inclusion were taught. ${ }^{\mathrm{x}}$ In this way, Bourdieu wrote that to develop social and cultural capitals was to learn what could also be valuable social and cultural behaviors and beliefs.

For instance, Bourdieu argued that capital was primarily acquired through what he referred to as agencies, such as the family, peer groups, schools, universities, clubs or societies. Furthermore, social and cultural capitals fed their way into the human subconscious, making capital values a part of human identity. On this, Bourdieu described 
capital values as "habitus," as they developed "principles which generate and organize practices." ${ }^{\prime x i}$

\section{Habitus and the development of capitals}

Bourdieu's theory of social and cultural capital values was not just useful to the sociologists and social philosophers that subsequently used it to discuss social divisions by like groups. Bourdieu's capitals also inspired a later generation of writers who examined people wrestling with their own identities, and experiences that had helped shape these identities. In the context of distinctions in learning, for example, contemporary social and cultural psychologists argued that habitus can also be thought of as internalized traditions.

For example, cultural capital has been linked to the development of knowledge of symbolic and ritualistic behavior that is a powerful part of belonging to a cultural community. ${ }^{x i i}$ Habitus has also been linked to disruptive behavior, the interruptions and denial of values that can lead to threats to our well-being and a sense of belonging in institutional spaces and places. ${ }^{\text {xiii }}$

What's more, in my previous studies I observed that in being restricted to traditional assistive technologies, people born blind rarely had a chance to try mainstream technologies. ${ }^{\text {xiv }}$ For instance, in many cases I found this different experience of the value of technology meant students lacked the capital to use or want mainstream computers even if they had successful careers in computing.

Unfortunately, lacking cultural capital value can also mean lacking knowledge of one's own culture, including knowledge of prevailing technologies that can enhance, deepen or further learning. For example, knowledge of mainstream technology can allow students to develop the habitus of accessing information from on-line academic sources. Subsequently, 
this habitus can allow students with disabilities to develop different cultural capital value, such as knowledge from the contents of a book. ${ }^{\mathrm{xv}}$

Consequently, the process of developing capital value can lead to new and further knowledge and habits, and support a confident, educated, "successful" and included identity. This new identity preserves cultural capital through higher and further learning, reinforcing a valuable cultural identity, so that different forms of learning become a habit. As this process continues, mainstream learning, and the use of mainstream technologies becomes more habitualized and a significant part of an individual's identity. ${ }^{\text {xvi }}$

It is through this cycle of habituation that the practice of knowing a field of study such as a subject learnt at school or university, a trade or profession, or a genre or artistic specialism - is key to the development of the value of cultural practice. Bourdieu felt that it was through this development that people could distinguish those with certain qualities of capital values from those without. This evolution of practice he expressed through the following formula:

$$
[(\text { habitus })(\text { capital })]+\text { field }=\text { practice }^{\mathrm{xvii}}
$$

\section{Technical capital as a form of cultural capital value}

Many derivatives of Bourdieu's writing on social and cultural capital values have been written to explain learning in the modern era. Perhaps the most relevant interpretations of the study I developed for this book is Sarita Yardi's notion of the existence of technical capital. $^{\text {xviii }}$

Yardi defined technical capital as, "the availability of technical resources in a network, and the mobilization of these resources in ways that can positively impact access to information and upward mobility." "xix Consequently, Yardi problematized technical capital as a form of cultural capital, as it was principally associated with education and similar cultural 
practices - in Distinction, Bourdieu had himself mentioned the use of technology as part of valuable cultural development.

In this study, technical capital value was also found to be a useful foundation for a notion of the value of inclusion, as it imagined the development of cultural capital as inclusion in cultural activities for a specific purpose. What's more, and as I show later in this book, these cultural activities could be seen as explaining issues of more formal institutional education.

What's more, in my earlier studies of cultural heritage I also found that technical capital was associated with developing forms of value, such as capitals associated with employment or human relationships. Consequently, soft-skills could equate to a part of technical capital in the study of access to broader forms of cultural institutions.

For instance, although ubiquitous for many sighted people, I discovered the ability to zoom in on digital images on the web enabled soft-skills that enabled access to other graphics. Furthermore, being able to interpret graphics could be seen as improving inclusion in other forms of visual education and training. This reasoning led me to ask, could the knowledge and skills used to value our basic human need, the need to feel included, be its own form of capital?

To address this central question, I referred to this idea as inclusive capital, and defined it as the sense of inclusion we all need to feel. What follows is a description of a model of inclusive capital.

\section{$\underline{\text { Inclusive Capital }}$}

\section{Capital as a sense of inclusion}


The previous studies of human value have, I would argue, a common theme. This theme is, they value a sense of inclusion and a sense of loyalty to a category of people as part of our human condition to feel included and to feel part of a network - e.g. few value family, friends, social class, religion, ethnicity, or a sense of being part of a disabled or non-disabled community. Subsequently, these philosophies agree it is important, if not instinctive, for people to network and to learn through others.

To put it another way: although there are better and worse ways of networking and learning, and we can be encouraged to use one way over another, because we don't learn to network and learn, we simply network and learn. Networking and learning is therefore arguably part of our human, perhaps even mammalian, condition.

Technical capital also shows us that it is important to get information and to use it to feel included, and it is a large part of our human history to develop and use technology; just as it can also be said to be part of our history to seek out our heritage and the heritage of others.

It could also be said that it is part of our human character to seek out inclusion as a value to feel our sense of inclusion; and it can be said that throughout history, people have fought wars, crossed continents hidden or fled from oppressors to form new communities, to feel secure and to feel a sense of inclusion. Consequently, to develop inclusive capital can also then be central to our human history.

Later in this book, I argue that acquiring inclusive capital is especially important if you are a disabled or an older person. This difficulty is caused because people with disabilities are more likely to find it harder to access the first steps of inclusive capital. This leads to a lessening of their sense of inclusion in mainstream society, and to a growing sense of social exclusion and isolation. 
For instance, disabled people often find it harder to access technologies they can interact with, or to access the environments of cultural institutions. They are less likely to have their needs understood, or be thought of as needing access to the learning of nondisabled people. They are often thought to want separate cultural institutions, such as schools or classes, or separate museum entrances or exhibitions in museums. They are consequently more likely to feel a sense of passive exclusion.

The physical nature of some disabilities or infirmities caused by old age can also lessen our access to the cycle of acquiring inclusive capital. For instance, acquiring deafness and blindness may make it harder to join group discussions that were once normal and are an essential part of networking, for gaining information or using technology. Physical disabilities may also make it harder to find transport or access cultural institutions or physical networks. Late acquired learning disabilities can similarly be thought to restrict access to mainstream learning, and the spaces and places of cultural institutions that people once enjoyed.

Therefore, it is another task of this book to develop an argument that cultural institutions and teachers need to recognize the need for inclusive capital, to foster a sense of inclusion. Cultural institutions and teachers do not just need to understand this sense of inclusion intellectually and academically, they need to feel empathy with this sense of inclusion.

Practically, cultural institutions and teachers must also understand and study ways in which they can adapt their spaces and places - both their physical and virtual environments. These institutions and teachers also need to adapt their own behavior to develop habits and practices that recognizes a sense of inclusion in others. 
To develop this argument and to understand the evidence for cultural inclusion in the cases in the later chapters, I start by developing the academic background developing inclusive capital from human values. The process of developing this background will structure the model of inclusive capital as a framework of different stages of development, which can be used in the later chapters.

\section{Five stages of developing inclusive capital}

As with other forms of capital, inclusive capital is not born in us, it is acquired. In common with all previous descriptions of capital, it can be said that a single cycle of acquiring inclusive capital is in five stages.

The first stage in this cycle is connecting and bonding with a network of people - that is to say, to acquire bonds from our human necessity to bond. These groups are largely seen as a family or a group of friends, classmates or workmates or, as Yardi observed, connecting and bonding with a group developed through social media.

Without connecting and bonding to this social or cultural network, there is no sense of inclusion. Consequently, our sense of inclusion is premised on a social and cultural process of feeling valued in these bonds and connections.

The second stage in this cycle is learning inclusive capital through our networks - that is to say, we use our human condition to learn to develop and acquire human capital. Consequently, learning inclusive capital consists of acquiring habits, knowledge and practices that can lead to a sense of inclusion. In common with the writing of Marx, part of this learning of inclusive capital is also seeing ourselves as being as equally included as others are in order to humanize our skills.

However, unlike Marx's understanding of morals, this is also where we develop a further sense, this is the moral sense of justice, which can also be described as a form of 
moral knowledge. In this respect, justice is also connected to a process of bonding, connecting and feeling included, and being included could be said to be an important part of our moral understanding.

The third stage in this cycle is collecting information that points to or later leads to knowledge. This collection of information can include finding out about our surroundings, making judgements about their worth or planning to travel within our surroundings. For example, this information could be directions from maps.

According to Yardi and Bourdieu, this third stage in the cycle can also be acquired through the use of technology, or gaining information to update inclusive capital. In the modern era, this third stage can also mean accessing digital networks or learning, and access to these networks and this learning can help develop a sense of inclusion.

Information is consequently a vital part of planning and designing inclusive capital, and its subsequent habits and practice. It can be described as the raw material or the atomic level of inclusive capital.

The fourth stage in this cycle is physical or virtual access to spaces and places, such as visiting or attending cultural institutions or reading about their collections and history these institutions can include schools, parks, universities, museums, cinemas, theatres, shops, workplaces, or as Yardi argues surfing websites.

The fifth stage in this cycle is a form of capital that weaves its way through all other forms of capital, and subsequently must be seen as a thread within rather than separate to other capitals. This capital is physical and virtual mobility, and is a capital that allows a person to navigate around their spaces and places, networks, and sources of information and learning - this can include surfing the Web for information, moving to make your way around an institutional environment or between environments, or even making contact with 
family through technologies such as telephones. Moreover, lacking mobility can lead to exclusion; to being unable to attend the institution as a place, to being unable to find information, or to being unable to move between networks of friends and family.

As these previous philosophies observe, although our networks do not have to be in a single place, we need an area - either physical or virtual - where we can access them. This access is important for connecting and bonding within our networks, or communicating with them. We also need access to cultural environments, or cultural objects or performances, that connect and bond us to our networks, or allow us to see our networks in relation to others' networks.

These five stages are represented in Figure 1 below.

Figure 1: The development of inclusive capital and a sense of inclusion

\section{FIGURE 1 HERE}

So, how can these four stages of developing inclusive capital be implemented in cultural institutions?

In this book, it is also important to define how cultural institutions can support the development of inclusive capital and access to their information, spaces and places. This definition is designed to help the reader understand the nature of the evidence I discuss in the following chapters. This process now follows.

\section{What are inclusive cultural institutions?}

In this study, inclusive cultural institutions are not just institutions in the traditional sense of the word. For example, when we normally talk about institutions, particularly cultural institutions, we usually imagine a museum, monument or gallery; perhaps we also 
imagine a church, a synagogue, a mosque or a temple, or perhaps a school or university. However, in this book I am going beyond this mental image.

The inclusive cultural institutions I write about in this book have two functions: the first function is to support people, and to provide some form of inclusion; the second function is to provide access to culture and learning, this culture being a part of someone's heritage.

Cultural institutions can be said to have three basic elements: they must have some form of human creator; they must have a form of administration; they must have a founding philosophy or reason, even if it has become distorted or invisible with time, to justify their existence. To make institutions cultural, they must also provide a sense of belonging, and often they must also be public and offer a sense of well-being and fascination to outsiders too. This casts my net a little wider than simply museums, religious buildings and schools.

For example, the town I live in can be said to be an inclusive cultural institution in many respects. This town in rural Wiltshire, in the UK, and it is a place and space that attracts and is made open to tourists, Christian pilgrims and locals from the town alike.

From the streets, you can see beautiful houses, an Anglo-Saxon church, a stone bridge with a chapel, a medieval tithe barn, a pilgrim route, a canal and tow path, an ancient river and ford, and rows of shops and tea houses. We also have public farmland donated over a hundred years ago to the people of the town, with paths, coppices, fields and nature areas, which like the town is administered by the town council.

In common with the first stage of developing inclusive capital through networks, locals, tourists and pilgrims climb the hills in groups, and we have organized tours and a walking club. The pilgrims also visit the chapels and pray in the churches where they meet fellow pilgrims. Tourists and locals can come together in buses, and the council provides areas where these buses can park. 
My town also has cafes, pubs and restaurants where all people can mingle, talk and network. Locals also network in town clubs, societies and churches. Families are also provided for through family and children's clubs, schools and nurseries, and a local café has a play area upstairs where children and parents meet over a coffee and their children play.

In common with the second stage of developing inclusive capital, locals and people from further afield can also feel a sense of belonging through learning. These communities learn something about the architecture and history of the town when they visit, through leaflets from the tourist office, from books and from the town website.

The pilgrims who visit the town gain something from their faith through information from the churches, websites and books about the tourist routes. Maps also provide information about accessing the route to different sites.

Tourists also get information and develop knowledge from the town through the sign posts and the plaques describing the area. They can also read books about the town, and understand a place that is different from their usual network or discover a history of their network they rarely get a chance to see.

In common with the third stage of gaining inclusive capital, my town's website gives information about the town's history and geography, and how to get to it, stay and leave it. There are also many individual websites for shops, hotels, our music centre and other smaller spaces and places that make up the town. There are also many town Facebook and Twitter groups, and images on town Instagram accounts.

Our town library has computers that can be booked and used by the public. There are also public Wi-Fi and telephone networks for wireless technologies, and plugs available in pubs, cafes and libraries where people can charge their laptops, tablets and telephones. The 
council, through its community centers and libraries, also provide computing courses that develop skills, and allow people to do everyday tasks, such as shopping on the Web.

In common with the fourth stage of developing inclusive capital, my local streets are administered by the town and county council, who try to be sensitive to and include our visitors. The councils put up sign-posts, pave and tar the streets, and even run a small tourist office in the town centre, with maps and brochures to educate its customers.

Our local councils also light and clean our streets, our river, our canal and our tow paths to make them feel safe; they cut back foliage when it gets out of hand; and they protect the local ducks and swans. The council also thinks of transport into and out of our town, and paints lines and provides parking for cars, shelters for buses and paths to our train station. All this activity makes our town more accessible, and most visitors find visiting our town a good experience.

Consequently, tourists get to see a type of stone in the buildings that perhaps they wouldn't see where they live. They see art that is different and interesting. Their children get to play in the river at the ford. So, many of those who visit my town get something from their visits, and feel a sense of inclusion from their visit to the space and place.

As the art historian Ernst Gombrich said of museums, my town's aim can be said to give, "profit and delight"xx to those who visit it.

Similarly, inclusive cultural institutions don't have to have, or just have, a physical space for the public to visit. They also don't have to be local in the modern age of information and technology.

Cultural institutions can also be a state of mind or a theoretical space, with a physical though not geographical "centre" or "centres," and cultural objects scattered throughout other spaces. The physical impression of the institution in that space and place also gives visitors a 
sense of place within their imaginative space and imaginative bonds, what I will call an imagined institution. Three very different examples of these imagined institutions illustrate their character and structure as a place and space.

The first example of an imagined institution is a digital social network.

What we call digital communities have arguably changed the way we think and write about culture in our modern era. They are so young, in effect, that they only really started to exist around forty years before Bourdieu conducted his survey of French culture. Subsequently, we can suggest that Bourdieu's description of his original survey of French cultural capital would look very different nowadays.

For example, as a member of Facebook and LinkedIn, I am socially connected with people worldwide, many of which I have never met in person or are unlikely to ever meet. This makes the notion of cultural capital different to the local or national cultures that Bourdieu described, much as Bourdieu redefined Marx and Smith's ideas when he wrote.

I am also members of societies, clubs and associations that only exist on the Web, such as arts discussion groups, philosophy societies and technology discussion "rooms." I have no or little physical image of the people I meet or have discussions with in these groups, associations or societies.

As a technologist, I know there are servers that hold, control and monitor my discussions and networking - maybe these servers are in California, perhaps in India. However, there is no physical space or place of these conversations, especially as my telephone and tablet are mobile.

During my online discussions, I also have no mental image of my discussants' clothes, or any knowledge of their social class. What's more, many of my discussants write in English as a second language, and I have no idea whether their accent is of one social class or 
another. This changes our idea of distinction of social class, ethnicity, level of education or artistic stature.

The second example of an imagined institution is national affiliation.

For example, this type of imagined institution was illustrated powerfully on Sunday 23rd April 2017, when the French presidential election was being reported by BBC news. As I watched the report from Paris at home, France was said by reporters to be in a state of "cultural crisis."

Media pundits and political scientists suggested that the French didn't understand their own identity anymore. Given the problems in the economy and mass immigration, it was argued, who knows what a French person is supposed to be, or what they are supposed to think of themselves. Supposedly, this crisis was causing an upheaval in the political process, both by native French people, and those who had recently moved to France.

On that night in Paris, the media reported the old guard had been rejected with embarrassing shares of the vote. The two political parties who had regularly swapped power for decades, had been usurped in a straight fight between what was described as a hard-right candidate and a "new" centrist candidate.

As if this cultural shift wasn't enough, it was reported that the hard-right candidate was a woman and the centrist was under forty. In the history of France, this was unheard of in matter of fact, the centrist was a former cabinet member of the then ruling party; and the woman candidate was the daughter of the previous leader of her party, and her father had been similarly successful a decade ago.

And yet, this was still recognizably France.

Membership of an imagined national institution is far more complex and robust than these reporters gave French nationals credit for. This form of imagined institutional identity is 
made-up of many, often disparate, elements. Most particularly, French people don't need to be resident in their homeland to be members of their imagined institution, and members of other nationalities often live easily in France. French nationals don't even need to have two French parents nowadays, or even to speak French.

It is true that some of the characteristics of our imagined institutions can be broadly defined according to our nationality. However, these elements of our national identities, which are compulsory in the modern Western world, are more likely to be imposed on us rather than are chosen or born into us.

Subsequently, imagined institutional membership can't be imagined according to single issues or single concepts, which are often external to people's personalities. Most importantly, as nationals and members of similarly imagined institutions, we are not clones of our neighbors, or those whose external characteristics we are said to possess. Each nationality has its own unique identity that imposes itself onto our identities.

The third example of an imagined institution is a sports team or club.

As a type of institution, a sports team or club engenders a strong feeling of loyalty and belonging, which itself forms a sense of inclusion. For instance, I chose to be a Liverpool soccer fan as a child. As a fan, my social rules, engagement and language of soccer is now the same as a Manchester United fan, but yet I' insulted to be compared to a Manchester United fan - and I'd imagine Manchester United fans feel the same.

Liverpool, more than any other sports team provide me with a distinct culture, and as a younger single man I was also a proud member of its fan club. This, I would argue, makes me culturally a Liverpool FC fan.

I have a Liverpool shirt, bag, mug, badges, old tickets and programs from matches, and the knowledge of current and past teams tucked in my memory. Steven Gerard, Kenny 
Dalglish, Kevin Keegan, Bill Shankly, Bob Paisley, and now Jurgen Klopp - to mention only a few - are my sporting icons. They represent the state of mind and the modes of play that is Liverpool FC.

Another loyalty is my baseball team, the New York Mets, honed by my short time living in New York with my family. In 2011, we lived in Queens, New York, and the Mets' stadium in Flushing Meadows was near our apartment, and so this became our team. Consequently, my family and I supposedly had the wrong nationalities for our household British and Italian - but the right baseball team.

Being Met's fans, we also resented the Yankees, the larger baseball team based in the Bronx. What's more, like Manchester City fans back in England, my family and I shared a homely and common dislike of the Yankees with Boston Red Sox fans.

Even years after leaving New York City, I still feel this sense of loyalty to the Mets, wear my Mets cap and feel a bond when I see another Mets cap wearer. I even watch the team on television when I'm back in the US. I don't live near the centre of the institution, or even on the same continent, but I still feel included in the institution.

\section{Discussion}

Philosophies of human value, an imagined form of knowledge, habits and behavior, has evolved over the two and a half centuries since Smith wrote The Wealth of Nations. Prior to the twentieth century, these philosophies moved from the ownership of human bodies to the control of human labor.

This vision of value as being more mind than the body led Marx to call for social justice for human value, and its ownership to be passed to those who created it. Subsequently, value became a part of human well-being and a sense of feeling valued, and having your 
humanity appropriately valued. However, like Smith, this social justice was based on an understanding that human behavior still had a financial capital value that should be bought and sold on through the market.

In the modern era, this philosophical link between financial value and human labor has been challenged. With this challenge, value has also come to be seen as a non-economic commodity, or a non-economic capital, and viewed more as a psychological and social difference learnt through the codes we are raised with.

These codes can include habits we observe around us daily, the formal and informal knowledge we are taught by friends, family and education, or the street-smarts we pick up as young people. What's more, these codes can't be easily bought and sold, or bought at all. They have a very different sense of value as an artisanal commodity, much as Marx argued production existed prior to the industrial revolution.

This new image of value allows us to see how capital can be a type of a non-economic commodity, a non-academic knowledge - including knowledge about how to use our academic knowledge - or an informal skill that we can apply to our daily lives.

Subsequently, philosophers such as Bourdieu and Yardi's ideas provide a further use for notions of value: the notion that capital can also be our motivation, our morals, our ethics, our well-being and our dignity; and that inclusion, the sense of inclusion I wrote about earlier in this chapter, is itself a capital, and the means of getting it can also be a capital with a very real human value.

By developing an image of capital as these other types of non-economic, psychological and cultural commodities do, we immediately broaden the ways we can develop inclusion. Inclusion is no longer merely the opposite of exclusion, and particularly the opposite of social exclusion, it is also a human value. 
Seeing inclusion as a form of capital allows us to go about developing it as an active process, one in which the person with an impairment or difficulty controls its development according to their needs. It also allows people from different backgrounds to develop their own capitals according to their needs, their backgrounds and their own cultural heritage.

Seeing inclusion as a capital also allows us to develop institutional strategies targeted at not just overcoming social injustice and singling out institutions who do not provide inclusive spaces and places. It also allows us to emphasize inclusion as a practical means of education that needs different practical learning strategies, and as a process of partnership with people deserving access.

In this respect, inclusive capital is a particularly powerful tool for people with disabilities in inclusive cultural institutions. Perhaps of all cultural communities, people with disabilities need more practical support to access and feel a sense of inclusion. This is largely because people with disabilities are also more vulnerable to changing identities, or having to develop a new identity when developing an impairment or difficulty. This process causes tensions in our sense of inclusion.

So, how can inclusive capital become useful to people with disabilities?

Moreover, how does inclusive capital effect disabled people's identities as they age, and develop different ways of accessing cultural heritage?

In the next section, I describe the development of inclusive capital through cases of learning about cultural heritage according to the different identities of disability I described in chapter two. I start this description with cases of developing inclusive capital as school students in chapters three and four. These students were either born with disabilities or developed disabilities at an early age. 
Chapters five and six describe the transition of inclusive capital whilst having a impairment or difficulty in old age. Chapter five looks at ageing as a person who was born with an impairment or difficulty or who developed one at a young age, and whose impairments or difficulties have become stronger in old age. Chapter six describes cases of people who have developed their impairments or difficulties in later life, and are adjusting their inclusive capital to maintain their well-being, and adjust their identities.

\section{$\underline{\text { References }}$}

Alexander, J. C. (1995). Fin de siècle social theory: Relativism, reduction and the problem of reason. New York: Verso.

Bourdieu, P. (1990). The logic of practice. Stanford, CA: Stanford University Press.

Bourdieu, P. (2010). Distinction. Abingdon, Oxford: Routledge Classics.

Chaney, D. (1996). Lifestyles. Abingdon, Oxford: Routledge.

Fowler, B. (1999). The sociology of habit: The perspective of Pierre Bourdieu. Variant, 2(8), $1-4$.

Gombrich, E.H. (1977). The museum: Past, present and future. Critical Inquiry, 3(3), 449470.

Hayhoe, S. (2012). Grounded theory and disability studies: Researching legacies of blindness. Amherst, NY: Cambria Press.

Hayhoe, S. (2012). Using an iPad with a blind student: A case study at Sharjah Women's College. In (Dowling, S., Gunn, C., Donaghue, Eds.), eLearning in action (Vol. 1): Opening up learning. Abu Dhabi: HCT Press. 
Hayhoe, S. (2015). Utilising mobile technologies for students with disabilities. In (Robertson, A \& Jones Parry, R. Eds.) Commonwealth education partnerships-2015 (Vol. 16). Cambridge: Commonwealth Secretariat \& Nexus Strategic Partnerships.

Hayhoe, S., Roger, K., Eldritch-Boersen, S \& Kelland, L. (2015). Developing inclusive technical capital beyond the Disabled Students' Allowance in England. Social Inclusion, 3(6), 29-41.

Lamont, M. (1992). Money, morals and manners: The culture of French and American uppermiddle class. Chicago: Chicago University Press.

Lizardo, O. (2004). The cognitive origins of Bourdieu's habitus. Journal for the Theory of Social Behavior, 34(4), 375-401.

Marx, K. (1986). Capital - A Critique of Political Economy: The Process of Production of Capital (Vol. 1). Moscow, Russia: Progress.

Riddell, S. \& Watson, N. (2010). Disability, culture and identity. London: Pearson.

Smith, A. (2005). Wealth of nations. Chicago, IL: University of Chicago Press.

Swartz, D.L. (2002). The sociology of habit: The perspective of Pierre Bourdieu. The Occupational Therapy Journal of Research, 22, 615-695.

Yardi, S. (2009). Social learning and technical capital on the social web. ACM Crossroads, $16(2), 9-11$.

Yardi, S. (2010). A theory of technical capital. Paper delivered to the TMSP Workshop, Georgia Institute of Technology, Georgia, US, February 11-12, 2010.

\footnotetext{
${ }^{\mathrm{i}}$ Smith (2005)

ii Smith (2005: P. 282)

iii Marx (1986)

iv Marx (1986: P. 28)

${ }^{v}$ Bourdieu (2010)

vi Lamont (1992)

vii Fowler (1999)

viii Chaney (1996) and Alexander (1995)

ix See for example, Riddell \& Watson (2010)
} 


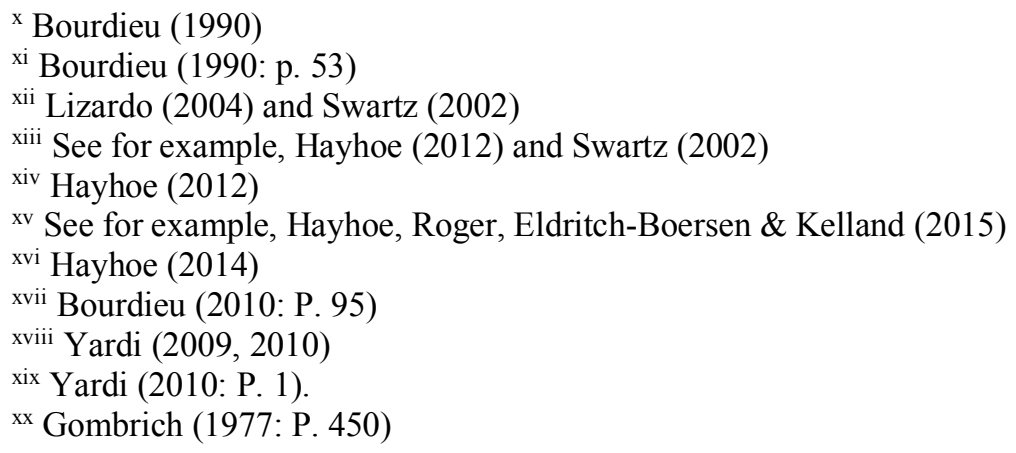

